\title{
Exercise studies in congenital heart block
}

\author{
Mervyn R. H. Taylor and Simon Godfrey \\ From The Institute of Diseases of the Chest, London
}

Bicycle exercise studies were performed on 4 patients with congenital heart block. Cardiac output was measured using the indirect $\left(\mathrm{CO}_{2}\right)$ Fick technique. Two patients were found to have a normal capacity for work but they both had low cardiac outputs at high work loads. The 2 patients who were unable to perform a normal amount of work had normal cardiac outputs on exercise at relatively low work loads. The degree to which a patient increased his ventricular rate or stroke volume was not related to the maximum work which he could perform. It is suggested that in these patients with very slow heart rates at work normal amounts of work can only be done if the patient can tolerate a low cardiac output, a large arteriovenous oxygen difference, and a low venous oxygen tension.

There have been many studies of cardiac function in patients with congenital heart block (Holmgren, Karlberg, and Pernow, 1959; Wright, Adams, and Anderson, 1959; Paul, Rudolph, and Nadas, 1958; Nakamura and Nadas, 1964; Moss, 1961; Wallgren and Winblad, 1937; Campbell and Thorne, 1956). However, there have been few reports of exercise tolerance, or of cardiac output measurements during exercise in patients with this condition who do not have artificial cardiac pacemakers (Ikkos and Hanson, I960; Moss, I96I ; Holmgren et al., 1959). Cardiac output at rest has been reported both as low (Wright et al., 1959) and normal (Paul et al., 1958; Moss, 196I). On exercise, too, the reports of cardiac output have been conflicting (Ikkos and Hanson, 1960; Holmgren et al., 1959).

This communication reports the exercise tolerance and cardiac performance of 4 patients with congenital heart block who do not have artificial cardiac pacemakers.

\section{Materials and methods}

Exercise tests were performed in the upright position on an electrically braked cycle ergometer as described elsewhere (Godfrey et al., 1971a). The exercise test was composed of two parts. A progressive exercise test was performed first, in which measurements were made of ventilation and heart rate while the work load was increased every minute up to a maximum that the subject could tolerate. After a 30-minute rest, steady state measurements were made in each subject at rest, one-third, and two-thirds of the maximum work load reached in the progressive test.

Expired gas was flushed through a large Tissot Received 17 January 1972. spirometer and analysed continuously for $\mathrm{O}_{2}$ and $\mathrm{CO}_{2}$. When pulse, minute ventilation, and expired gas concentration were all steady (after $2 \frac{1}{2}-3 \frac{1}{2}$ minutes), a collection of expired gas was made in the spirometer over at least one minute and analysed immediately. While the expired gas was being collected a sample of arterialized blood was taken from an ear lobe for estimation of $p \mathrm{H}$, $\mathrm{PO}_{2}$, and $\mathrm{PCO}_{2}$ (Godfrey et al., 197Ib). The mixed venous $\mathrm{PCO}_{2}$ was estimated by rebreathing a $\mathrm{CO}_{2}$ in oxygen mixture to obtain equilibration of $\mathrm{CO}_{2}$ tension between the gas mixture and the mixed venous blood (Jones et al., 1967; Denison et al., 1969). A downstream correction was not applied (Jones et al., 1967; Godfrey et al., 1971a).

Carbon dioxide production was calculated from the analysis of expired air, and the carbon dioxide content of arterial and mixed venous blood was calculated from the gas tensions using a $\mathrm{CO}_{2}$ dissociation curve and a digital computer programme (Godfrey, 1970). Cardiac output was calculated using the indirect $\left(\mathrm{CO}_{2}\right)$ Fick method:

$$
\text { Cardiac output }=\frac{\text { carbon dioxide production }}{\begin{array}{c}
\text { mixed venous }- \text { arterial carbon } \\
\text { dioxide content difference }
\end{array}}
$$

Mixed venous oxygen content was calculated from the cardiac output, the oxygen consumption, and the arterial oxygen content.

The arterial $\mathrm{PCO}_{2}$ used for the estimation of cardiac output was obtained either from arterialized ear lobe blood samples or derived from the Bohr equation assuming a normal dead space (Godfrey and Davies, I970). Arterial blood lactate rise was calculated by the method of Clode and Campbell (1969).

The normal values given are those which have been obtained in this laboratory using the same methods as in the present study (Godfrey et al., 1971a). 'Normal range' in all cases refers to two standard errors either side of the estimate for normal subjects. 
The physical characteristics and diagnostic details of the patients are given in Table I.

Congenital heart block was diagnosed in Case I at the age of 6 years. She was instructed never to exert herself and so she never played games at school and always led a sedentary life. Cardiac - catheterization revealed a normal cardiovascular system apart from the conduction defect. Congenital heart block was diagnosed at birth in Case 2. He has had exercise intolerance from childhood. When playing football at school he had to stop about every Io minutes because of dyspnoea. He complains of being tired in his present work as a waiter and suffers from mild

- bronchitis. Cardiac catheterization revealed only minimally increased right ventricular and pulmonary arterial pressures in addition to the anatomical lesions given in Table I. Congenital heart block was diagnosed in Case 3 at the age of Io years when he attended hospital because of a chest infection. Case 4 was delivered by caesarian section because of bradycardia. His heart rate

2 remained between 90 and 100 beats a minute after delivery and the diagnosis of congenital heart block was confirmed by an electrocardiogram. Cases 3 and 4 both take part in athletics and football without any difficulty whatsoever.

None of the patients had ever suffered from Adams-Stokes attacks, nor were any of them receiving any treatment at the time of the study. All of them had complete atrioventricular dissociation on their electrocardiograms.

\section{Results}

The progressive exercise test On exercise all patients showed an increase in both
TABLE I Patients

\begin{tabular}{llllll}
\hline $\begin{array}{l}\text { Case } \\
\text { No. }\end{array}$ & $\begin{array}{l}\text { Age } \\
(y r)\end{array}$ & Sex & $\begin{array}{l}\text { Height } \\
(\mathrm{cm})\end{array}$ & $\begin{array}{l}\text { Weight } \\
(\mathrm{kg})\end{array}$ & Associated cardiac abnormalities \\
\hline I & 23 & F & 160 & $51 \cdot 3$ & Nil \\
2 & 21 & M & $172 \cdot 5$ & $73 \cdot 4$ & $\begin{array}{l}\text { Dextrocardia and corrected trans- } \\
\text { position of great vessels }\end{array}$ \\
3 & $15 \frac{3}{4}$ & M & 169 & $58 \cdot 0$ & $\begin{array}{l}\text { Nil } \\
\text { Dextrocardia }\end{array}$ \\
4 & $9 \frac{1}{4}$ & M & 124 & $25 \cdot 5$ & \\
\hline
\end{tabular}

atrial and ventricular rate, but the atrial rate rose faster than the ventricular rate with increasing work (Fig. I). The rate of rise was greatest in the youngest patient. The atrial rate in all cases followed the same overall trend as in normal subjects and only in Case 3 did it fall outside the normal range at some work loads.

The increase in ventricular rate on work varied from patient to patient. From rest to maximum work Cases $I$ and 3 increased their ventricular rate by 60 beats a minute, Case 2 by 31 beats a minute, and Case 4 by 20 beats a minute. The maximum work load that a patient was able to complete was not related to his rise in ventricular rate. Case 4 , with the smallest rise in ventricular rate ( 20 beats/ minute), reached a normal maximum work for his size. Case 3 also reached a normal maximum work load, while Cases $I$ and 2 did not reach their normal maximum loads (I40 and $210 \mathrm{~W}$, respectively).

- FIG. I The atrial rate $(0)$ and the ventricular rate $(\bullet)$ for each patient in the progressive exercise test plotted against the work load. The shaded areas represent 2 standard errors either side of the regression line for normal subjects of the same height.

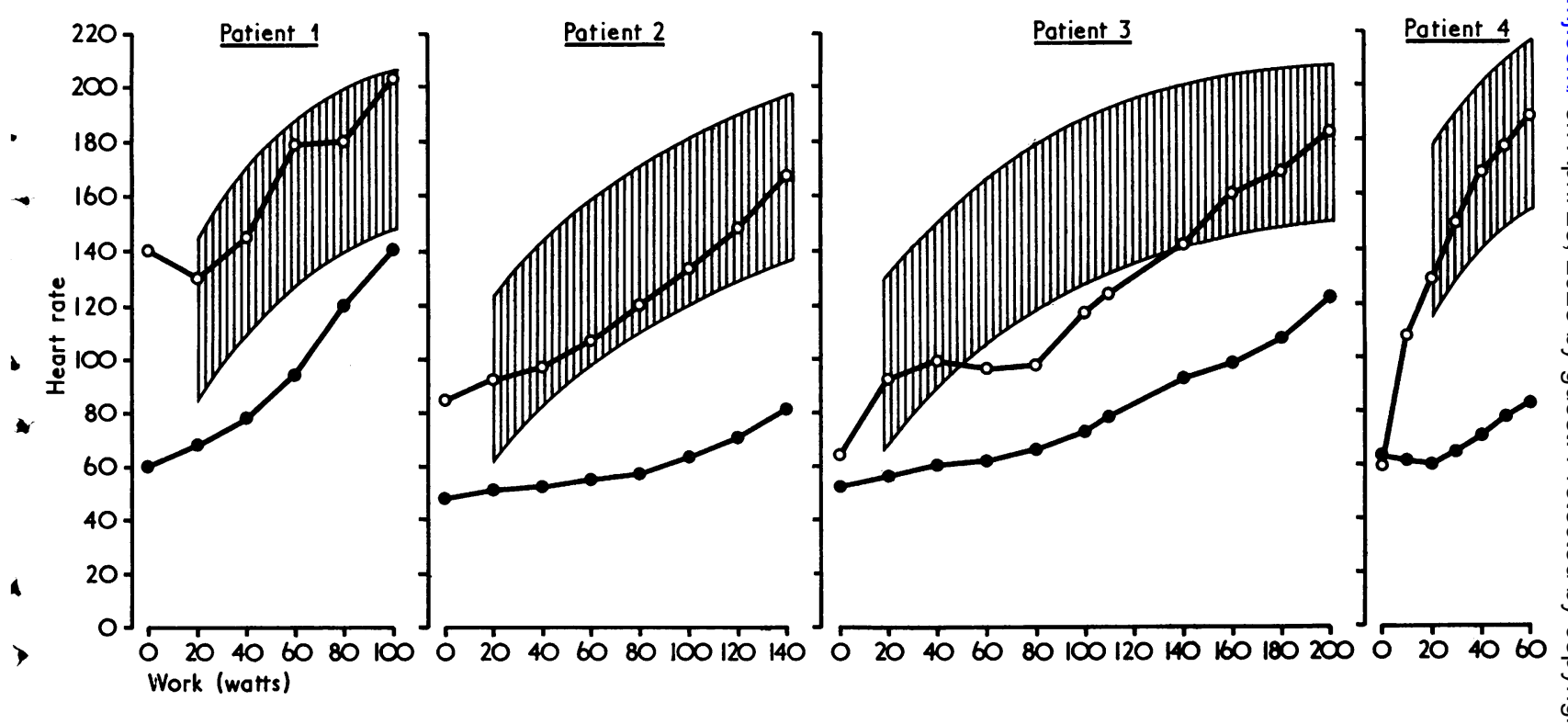




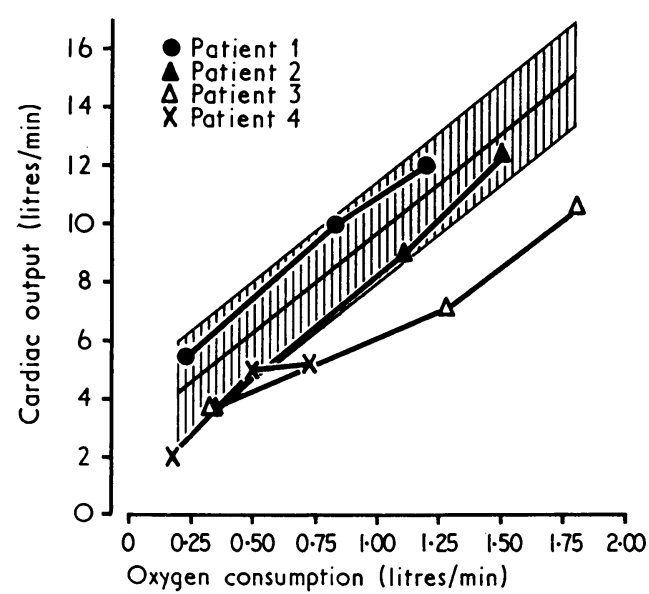

FIG. 2 The cardiac output for each patient plotted against oxygen consumption. The heavy line represents the regression line for normal subjects and the shaded area two standard errors either side.

Most normal subjects have a heart rate in the range $175-195$ beats/minute at their maximum work load (Godfrey et al., I971a). Three of the patients in this study had atrial rates in excess of $\mathrm{I} 80$ beats a minute at their maximum work load. In general the atrial response to exercise was normal but the ventricular increase in rate was below normal.

Minute ventilation was normal throughout the progressive exercise test except in Case $I$ where it was increased by $\mathrm{I} \cdot 8 \mathrm{l} /$ /minute above the normal range during the last work load.
TABLE 2 Results for steady state exercise test in 4 patients (mean values for normal subjects are given in brackets)

\begin{tabular}{|c|c|c|c|c|c|c|}
\hline $\begin{array}{l}\text { Case } \\
\text { No. }\end{array}$ & $\begin{array}{l}\text { Work } \\
(W)\end{array}$ & $\begin{array}{l}\text { Minute } \\
\text { ventilation } \\
\text { (l./min BTPS) }\end{array}$ & $\begin{array}{l}\text { Oxygen } \\
\text { consumption } \\
(\text { (l./min STPD) }\end{array}$ & $\begin{array}{l}\text { Arterial } \\
\mathrm{PCO}_{2} \\
(\mathrm{mmHg})\end{array}$ & $\begin{array}{l}\text { Cardiac } \\
\text { output } \\
(\text { l. } / \text { min })\end{array}$ & $\begin{array}{l}\text { Ven- } \frac{\sigma}{\overline{\bar{S}}} \\
\text { tricular } \\
\text { ratelmin } \frac{\mathbb{\Phi}}{2}\end{array}$ \\
\hline $\mathbf{I}$ & $\begin{array}{r}0 \\
33 \\
66\end{array}$ & $\begin{array}{l}10.8(10) \\
32 \cdot 9(25) \\
52.0(35)\end{array}$ & $\begin{array}{c}214(330) \\
827(720) \\
1213(I 120)\end{array}$ & $\begin{array}{l}21 \cdot 5 \\
31 \cdot 2 \\
28 \cdot 2\end{array}$ & $\begin{array}{c}5.4(4.5) \\
9.8(8 \cdot 5) \\
11.4(11 \cdot 0)\end{array}$ & $\begin{array}{r}63 \\
87 \text { (I } 4 \\
114 \text { (I9 }\end{array}$ \\
\hline 2 & $\begin{array}{r}0 \\
47 \\
95\end{array}$ & $\begin{array}{l}12 \quad(10) \\
36 \cdot 7(32) \\
56 \cdot 8(42)\end{array}$ & $\begin{array}{l}334(320) \\
\text { I } 105(900) \\
1498(1460)\end{array}$ & $\begin{array}{l}24 \cdot 8 \\
34 \cdot 2 \\
33 \cdot 9\end{array}$ & $\begin{array}{c}3.6(5.4) \\
8 \cdot 7(10 \cdot 2) \\
12 \cdot 2(12 \cdot 8)\end{array}$ & $\begin{array}{l}52 \\
55(13 \\
72(15\end{array}$ \\
\hline 3 & $\begin{array}{r}0 \\
66 \\
132\end{array}$ & $\begin{array}{l}12 \cdot 9(10) \\
37 \cdot 7(36) \\
54 \cdot 1(50)\end{array}$ & $\begin{array}{c}312(320) \\
1268(1120) \\
1810(1880)\end{array}$ & $\begin{array}{l}32 \cdot 3 \\
31 \cdot 0 \\
32 \cdot 5\end{array}$ & $\begin{array}{c}3.6(5 \cdot I) \\
7 \cdot 0(11 \cdot 4) \\
10.5(14.8)\end{array}$ & $\begin{array}{l}56 \\
63(146 \\
87(17)\end{array}$ \\
\hline 4 & $\begin{array}{r}0 \\
20 \\
40\end{array}$ & $\begin{array}{c}5 \cdot 3(8) \\
18 \cdot 9(18) \\
26 \cdot 0(23)\end{array}$ & $\begin{array}{l}158(150) \\
528(550) \\
712(800)\end{array}$ & $\begin{array}{l}33 \cdot 8 \\
33 \cdot 0 \\
30 \cdot 3\end{array}$ & $\begin{array}{l}2 \cdot 0(4 \cdot 0) \\
5 \cdot 0(6 \cdot 4) \\
5 \cdot 1(7 \cdot 8)\end{array}$ & $\begin{array}{l}59 \\
70 \text { (139) } \\
82 \text { (160 }\end{array}$ \\
\hline
\end{tabular}

Steady state tests The results of the steady state tests are given in Table 2.

Cardiac output The results for cardiac output in relation to oxygen consumption are given in Fig. 2. Cardiac output was normal at rest in all cases except Case 4, in whom it was low. On exercise cardiac output increased in all cases. The results for Cases I and 2 were normal at both levels of exercise. Case 4 had a cardiac output within normal limits at the first work load but a low output at the second work load. Case 3 had a low cardiac output at both work loads.

FIG. 3 The stroke volume for each patient plotted against the oxygen consumption. The shaded area represents two standard errors either side of the regression line for normal subjects of the same height.

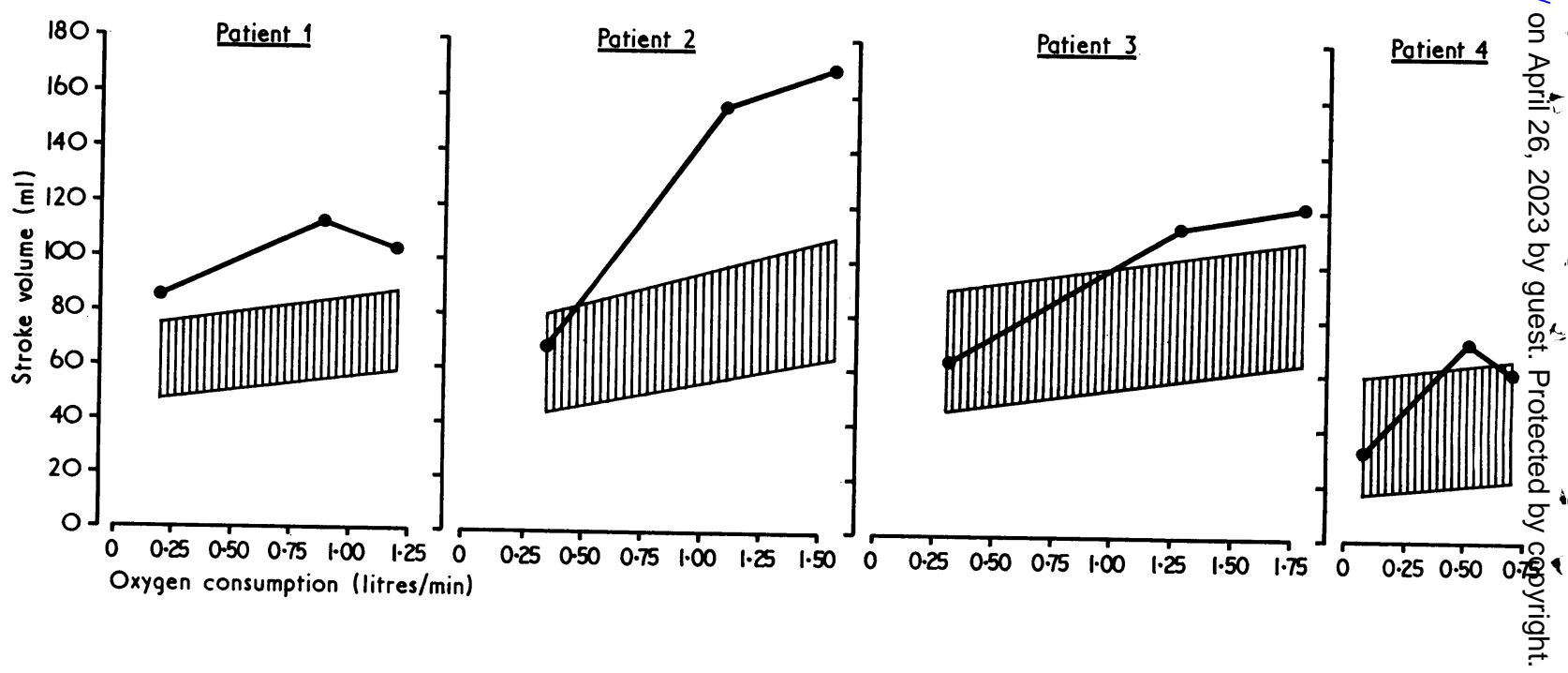


Stroke volume In Fig. 3 stroke volume for each patient is plotted against oxygen consumption and the normal ranges given.

All patients had a large rise in stroke volume between rest and exercise with only a small further change between the first and second work loads. Only in Case I was the stroke volume abnormally large at rest. At work all patients had a stroke volume greater than normal except Case 4 whose stroke volume was just within normal limits during the second work load.

- Minute ventilation During the second steady state work load, Cases I and 2 both had a raised minute ventilation. At rest and at the first work load they both had a normal minute ventilation. In Cases 3 and 4 minute

1 ventilation was normal. All the patients had moderate alveolar hyperventilation, as shown

$\checkmark$ by the low arterial $\mathrm{PCO}_{2}$ values.

Other investigations Venous admixture was normal in all patients. Calculated lactate rise never increased above normal values in any subject.

\section{Discussion}

Progressive exercise test Ikkos and Hanson (1960) assessed the maximum working capacity of ro patients with congenital heart block. They found that 6 of the patients had a normal working capacity and in 4 it was slightly reduced. Holmgren et al. (1959) - studied 4 patients with this condition and found that the maximum working capacity was low in $\mathbf{3}$ of them and normal in only one. Moss (196I) found a normal working capacity in all of the 4 children he studied with congenital heart block. In the present study 2 patients had a normal maximum working capacity as measured in the progressive test and in the other 2 it was low.

- Heart rate and rhythm Ikkos and Hanson (I960), using a two work load test, noted that the rise in ventricular rate with work was not smooth. They found a large increase between rest and the first work load and a smaller in-

- crease between the first and second work loads. This occurred in the present study

- during the steady state test, but in the progressive test where small work increments were used, the ventricular rate rose smoothly as the work load increased (Fig. I).

Case I was somewhat apprehensive at the

4 start of her progressive test and had an atrial rate of 144 beats a minute and a ventricular rate of 59 beats a minute at rest. At rest, during the steady state study, when she was less apprehensive, the figures were I I 9 beats a minute and 63 beats a minute, respectively. It appears that emotion affects the atrial but not the ventricular rate.

Moss and Adams (1968) have stated that the ventricular and atrial rates generally parallel each other. It can be seen in Fig. I that this only occurred in I of the 4 patients in this study (Case $\mathrm{I}$ ). They also state that heart rate remains quite constant (40-80) from before birth to the adult age group. Case 4 had a ventricular rate of 90 to 100 beats/minute at birth and a rate of 80 to 90 beats/minute after 40 hours of age. His ventricular rate at rest is now 62 beats a minute.

Case 2 had no extrasystoles at any time. Case 3 developed ventricular extrasystoles at the Ioo watt load and they remained present at all higher work loads. The extrasystoles disappeared almost immediately he stopped work. Case I followed the same pattern but the extrasystoles first appeared at the 80 watt load. Case 4 had frequent ventricular extrasystoles both at rest and on exercise. Ikkos and Hanson (1960) noted ventricular extrasystoles on exercise in 6 of their I I patients while Holmgren et al. (1959) found them in 2 out of 4 patients and Moss and Adams (1968) in 2 out of ro patients during exercise.

Steady state test The 2 patients (Cases I and 2) who failed to reach a normal maximum work load in the progressive test had normal cardiac outputs in the steady state test at relatively low work loads. Both of the patients who reached a normal maximum work load in the progressive test had a low cardiac output at the higher work load in the steady state test. The increase in stroke volume which occurred on work, though greater than normal, was insufficient to compensate for the slow ventricular rate. In order to reach a normal maximum work load these patients had to tolerate a low cardiac output and, as a consequence, an extremely low oxygen content of their venous blood (Table 3). The calculated arteriovenous oxygen differences in these two patients were greater than the highest values reported by Ekblom and Hermansen (1968) in a study of Swedish athletes. The small changes in the calculated lactate rise suggest that anaerobic metabolism did not play a large part in energy production.

That the venous oxygen saturation may be a limiting factor for work in patients with heart block is suggested by the work of Edhag and Zetterquist (1968) in adults with artificial cardiac pacemakers. They found that the mean femoral venous oxygen saturation at which their patients stopped work was similar whe- 
TABLE 3 Calculated values for arterial oxygen content in $\mathrm{ml} / \mathrm{IOO} \mathrm{ml}$ blood $\left(\mathrm{C}_{a} \mathrm{O}_{2}\right)$, mixed venous oxygen content in $\mathrm{ml} / 100 \mathrm{ml}$ blood $\left(C_{\bar{v}} \mathrm{o}_{2}\right)$, mixed venous partial pressure of oxygen in $\mathrm{mmHg}\left(\mathrm{P}_{v} \mathrm{o}_{2}\right)$, and mixed venous oxygen saturation per cent $\left(S_{\bar{v}} o_{2}\right)$ at rest and on exercise in 4 patients

\begin{tabular}{|c|c|c|c|c|c|}
\hline $\begin{array}{l}\text { Case } \\
\text { No. }\end{array}$ & $\begin{array}{l}\text { Work } \\
(W)\end{array}$ & $C_{a} o_{2}$ & $C_{\bar{v} o_{2}}$ & $P_{v} o_{2}$ & $S_{\bar{v} o_{2}}^{-}$ \\
\hline I & $\begin{array}{r}0 \\
33 \\
66\end{array}$ & $\begin{array}{l}2 I \cdot 5 \\
2 I \cdot 3 \\
2 I \cdot I\end{array}$ & $\begin{array}{l}17.5 \\
12.8 \\
10.8\end{array}$ & $\begin{array}{l}86 \\
31 \\
33\end{array}$ & $\begin{array}{l}82 \\
60 \\
50\end{array}$ \\
\hline 2 & $\begin{array}{r}0 \\
47 \\
95\end{array}$ & $\begin{array}{l}20 \cdot 9 \\
2 I \cdot 3 \\
2 I \cdot I\end{array}$ & $\begin{array}{r}\text { I I } 6 \\
8 \cdot 6 \\
8 \cdot 8\end{array}$ & $\begin{array}{l}33 \\
25 \\
26\end{array}$ & $\begin{array}{l}53 \\
40 \\
41\end{array}$ \\
\hline 3 & $\begin{array}{r}0 \\
66 \\
133\end{array}$ & $\begin{array}{l}20.5 \\
20.6 \\
20.6\end{array}$ & $\begin{array}{r}\text { I I.9 } \\
2.5 \\
3.4\end{array}$ & $\begin{array}{l}26 \\
12 \\
13\end{array}$ & $\begin{array}{l}57 \\
12 \\
16\end{array}$ \\
\hline 4 & $\begin{array}{r}0 \\
20 \\
40\end{array}$ & $\begin{array}{l}17 \cdot 9 \\
\text { I } 8 \cdot 1 \\
\text { I } 8 \cdot 1\end{array}$ & $\begin{array}{r}10 \cdot 0 \\
7 \cdot 5 \\
4 \cdot 1\end{array}$ & $\begin{array}{l}30 \\
22 \\
15\end{array}$ & $\begin{array}{l}55 \\
41 \\
22\end{array}$ \\
\hline
\end{tabular}

ther the ventricular rate was 47 or 72 beats a minute, though the duration and severity of work performed was higher at the higher ventricular rate. It may be that the ability to tolerate a low venous oxygen tension has to be acquired by training and this could explain the differences in exercise tolerance in the present study. Both the subjects who had a normal exercise tolerance were very active and took part in field sports but this could be a reflection of their normal exercise tolerance rather than the cause of it.

The fact that 2 patients were able to continue work with low cardiac outputs suggests that cardiac output alone is not a limiting factor for work in congenital heart block, and so heart rate and stroke volume will not be limiting factors either. In these 4 patients the ability to reach a normal maximum work load was not related to the increase in ventricular rate, or in stroke volume on exercise.

Holmgren et al. (1959) have reported one patient with congenital heart block who had a normal exercise tolerance and a normal cardiac output at work but this patient was able to increase his ventricular rate by 75 beats a minute between rest and exercise which is greater than the increase of any of the patients in the present study. The second subject they studied had a low maximum working capacity and a slightly low cardiac output at work. This subject was only able to increase his ventricular rate by 34 beats a minute between rest and exercise.

The 2 patients studied by Ikkos and Han- son (1960) both had low maximum working capacities and normal cardiac outputs (assuming a normal oxygen consumption) at low levels of work. Their findings agree with the findings in the 2 patients in this study who had normal cardiac outputs at work.

It appears that subjects with congenital heart block who can produce only a small increase in ventricular rate can only achieve a normal work output if they can tolerate a low cardiac output relative to the work done.

The difference between the patients reaching a normal maximum work load and those failing to do so is presumably due to the response of the working muscle to increasing difficulty in extracting oxygen from the circulation. Had the patients with normal cardiac outputs reached a normal maximum work load without any further increase in cardiac output, they would have had to tolerate a low venous oxygen content. The ability to tolerate low venous oxygen contents may be the factor separating the two types of response to exercise and it is possible that this can be acquired by training.

The authors would like to thank the consultants of Brompton, Guy's, and Hillingdon Hospitals who allowed their patients to be studied, their technical and medical colleagues, and the patients themselves for their co-operation. This work was carried out under grants from the British Heart Foundation and the Chest and Heart Foundation. Dr. M. Taylor was in receipt of the Eden Fellowship in Paediatrics during the course of the study.

\section{References}

Campbell, M., and Thorne, M. G. (1956). Congenital heart block. British Heart fournal, 18, 90.

Clode, M., and Campbell, E. J. M.(1969). The relationship between gas exchange and changes in blood lactate concentrations during exercise. Clinical Science, 37, 263.

Denison, D., Edwards, R. H. T., Jones, G., and Pope, $H$. (1969). Direct and rebreathing estimates of the $\mathrm{O}_{2}$ and $\mathrm{CO}_{2}$ pressures in mixed venous blood. Respiration Physiology, 7, 326.

Edhag, O., and Zetterquist, S. (1968). Peripheral circulatory adaptation to exercise in restricted cardiac output. Scandinavian fournal of Clinical and Laboratory Investigation 21, 123.

Ekblom, B., and Hermansen, L. (1968). Cardiac output in athletes. Fournal of Applied Physiology, 25, 619.

Godfrey, S. (1970). The manipulation of the indirect Fick principle by a digital computer programme for the calculation of exercise physiology results. Respiration, 27, 513.

Godfrey, S., and Davies, C. T. M. (1970). Estimates of arterial $\mathrm{PCO}_{2}$ and their effect on the calculated values of cardiac output and dead space on exercise. Clinical Science, 39, 529.

Godfrey, S., Davies, C. T. M., Wozniak, E., and Barnes, C. A. (I971a). Cardio-respiratory response to exercise in normal children. Clinical Science, 40, 419. 
Godfrey, S., Wozniak, E. R., Courtenay Evans, R. J., and Samuels, C. S. (197I b). Ear lobe blood samples for blood gas analysis at rest and during exercise. British Fournal of Diseases of the Chest, 65, 58.

Holmgren, A., Karlberg, P., and Pernow, B. (1959). Circulatory adaption at rest and during muscular work in patients with complete heart block. Acta Medica Scandinavica, 164, 119.

Ikkos, D., and Hanson, J. S. (I960). Response to exercise in complete atrioventricular block. Circulation, 22, 583 .

Jones, N. L., Campbell, E. J. M., McHardy, G. J. R., Higgs, B. E., and Clode, M. (1967). The estimation of carbon dioxide pressure of mixed venous blood during exercise. Clinical Science, 32, $31 \mathrm{I}$.

Moss, A. J. (I96I). Congenital complete atrioventricular block. Clinical feature, haemodynamic findings and physical working capacity. Fournal-Lancet, 8I, 542.
Moss, A. J., and Adams, F. H. (1968). Heart Disease in Infants, Children and Adolescents. Williams and Wilkins, Baltimore.

Nakamura, F. F., and Nadas, A. S. (1964). Complete heart block in infants and children. New England fournal of Medicine, 270, 1261.

Paul, M. H., Rudolph, A. M., and Nadas, A. S. (1958). Congenital complete atrioventricular block: problems of clinical assessment. Circulation, 18, 183.

Wallgren, A., and Winblad, S. (1937). Congenital heart block. Acta Paediatrica, 20, 175.

Wright, F. S., Adams, P., and Anderson, R. C. (1959). Congenital atrioventricular dissociation due to complete or advanced atrioventricular heart block. American fournal of Diseases of Children, 98, 72.

Requests for reprints to Dr. Mervyn Taylor, Institute of Diseases of the Chest, Brompton Hospital, London S.W.3. 